\title{
RECONSTRUÇÃO DE PAISAGEM DA TERRA NATAL: A EXPERIÊNCIA DE TOHOKU, JAPÃO, APÓS TERREMOTO E TSUNAMI, EM 2011
}

\author{
Kelton Gabriel*
}

Humberto Tetsuya Yamaki**

Resumo: O objetivo do presente é apresentar a priori uma metodologia para analisar o processo de reconstrução de Tohoku, no Japão, região afetada pelo terremoto/tsunami de 2011, assim também como o processo da reconstrução da terra natal (furusato). Nessa fase da pesquisa, trabalha-se a identificação das etapas de reconstrução através das atividades até agora realizadas. Depois da etapa inicial emergencial, estão sendo discutidos processos de realocação e reconstrução de vilarejos e cidades preservando características consideradas identitárias para a comunidade. Por fim, apresenta-se o processo da reconstrução da terra natal, em que se propõe uma análise da consciência coletiva local e de sua capacidade de reter em suas estruturas subjetivas um senso de paisagem primordial de suas identidades.

Palavras-chave: terra natal, paisagem cultural, desastres naturais, reconstrução, Japão.

\section{RECONSTRUCTION OF HOMETOWN LANDSCAPE: TOHOKU - AFTER JAPAN EARTHQUAKE AND TSUNAMI IN 2011}

\begin{abstract}
This paper aims to present a methodology to analyze the process of reconstruction of Tohoku in Japan, the region affected by the earthquake / tsunami of 2011, so as the process of Reconstruction of the homeland (furusato). In this phase, the research will be centred to identify the stages of rebuilding through the activities carried out so far. After the initial emergency phase, processes are being discussed to the relocation and reconstruction of villages and towns preserving identity characteristics considered for the community. Finally it is proposed the called process of Reconstruction of the Homeland, which proposes an analysis of the collective consciousness and local capacity to retain in their structures a subjective sense of primordial landscape of their identities.
\end{abstract}

Keywords: homeland (furusato), cultural landscape, natural hazards, reconstruction, Japan.

\section{Introdução}

A relação do homem com o chão sempre foi de importância para a Geografia Cultural, no entanto essa relação no Japão ganha uma conotação diferenciada. 0 presente trabalho destina-se a investigar essas matrizes comportamentais existentes entre os japoneses de modo evidenciado, e que é conhecido como "furusato", literalmente: "terra natal".
Furusato literally means "old village," but its closer English equivalents are "home" and "native place". As a landscape, the quintessential features of furusato include forested mountains, fields cut by a meandering river, and a cluster of thatch-roof farm houses. Furusato also cannotes a desirable lifestyle aesthetic summed up by the term soboku, or artlessness and rustic simplicity. Today, furusato is one of the most popular symbols used by Japanese politicians, city planners, and advertisers (ROBERTSON, 1988, p. 494).

\footnotetext{
* Bacharel e licenciado em Geografia pela Universidade Estadual de Ponta Grossa. Mestre em Geografia pela Universidade Federal do Paraná. Doutorando em Geografia pela Universidade Estadual de Londrina. E-mail: kleiton.gabriel@gmail.com.

** Graduado em Arquitetura pela Universidade de São Paulo (1976). Mestre (1981) e doutor em Planejamento Ambiental (1984) pela Universidade de Osaka. Fez pós-doutorado em Desenho Urbano no JCUD - Oxford Polytechnic. Professor associado da Universidade Estadual de Londrina, leciona na Pós-graduação em Geografia (mestrado e doutorado) e no curso de Arquitetura e Urbanismo. E-mail: yamaki@ymail.com.
} 
O sentimento de pertencimento simbólico e identidade com o espaço fica mais evidenciado em momentos de catástrofes ou afastamento da "terra natal". Nesses momentos o sentimento de furusato é fortalecido em seu significado, pois apresenta-se como um mecanismo básico e essencial para a sobrevivência psicoespacial daquela pessoa. Aqui notamos outro conceito que nasce nessa separação ou perca da "terra natal", o sentimento de "nostalgia".

[...] Nostalgia is, in part, a state of being provoked by a dissatisfaction with the present on the grounds of a remembered, or imagined, past plenitude. It is a barometer of present moods. Nostalgia informs furusato, one of the most compelling Japanese tropes for cultural, social, and economic self-sufficiency in the face of vexatious domestic problems and the trials of "transnational capitalism" (ROBERTSON, 1995, p. 89).

\section{O conceito de furusato não trabalha}

apenas através do espaço construído pelo homem, mas sim engloba montanhas, florestas, campos, rios, lagos etc. e buscando essa etimologia original do conceito de "terra natal" no Japão pretende-se, portanto compreender e estudar o caso da reconstrução da área destruída de Tohoku no Japão via o conceito de "paisagem" de uso atual na Geografia. O conceito de paisagem na Geografia é baseado na concepção de ser um espaço capturado pelos cinco sentidos, além disso, há geógrafos que trabalham com a captação intuitiva do espaço, uma espécie de sexto sentido (ANDREOTTI, 2010).

Ever since its institution as a subject, Japanese historical geography has, in all associated research, had the landscape as one its underlying focus areas. The Japanese word keikan, which has become popular as a technical term not only in geography but also in other disciplines - instead of the word fukei which implies a visual and perceptual landscape - is a translation from the German Landschaft. This means that "landscape" in Japanese geography has been more of a regional or spatial concept, rather than a visual concept, and has often been used to convey a meaning similar to the word "region." The spatial plan or morphology of landscape had been the most important factor in many geographical works; this has led to some confusion when discussions have been held with scholars employing the English meaning of landscape, especially those from the W. Hoskins' school in England and C. Sauer's school of cultural geography (KINDA, 2010, p. 6).

Podemos perceber que de fato para capturarmos a realidade cotidiana de determinada localidade é preciso ir além da simples percepção, pois os aspectos intuitivos (sentimentos despertados pelos sentidos) norteiam a acepção espacial daquela localidade. Para isso precisamos estudar melhor os aspectos de uma psicologia ambiental levando em consideração fatores que não são captados de imediato, mas sim apenas após uma convivência lógica com a realidade fornecida.

O terremoto seguido de tsunami em Tohoku, no Japão, em 2011, resultou no desalojamento de 450.000 pessoas e em quase 25.000 vítimas mortas ou desaparecidas. Além disso, a catástrofe destruiu paisagens nacionais consideradas como patrimônio da humanidade e de cidades e vilarejos centenários. Cerca de 25 milhões de toneladas de entulhos foram retirados da superfície e do fundo do mar (há uma proposta de fazer uma ilha artificial com o entulho). Perante essa situação como se configura a reconstrução desse espaço? Quais seriam as simbologias empregadas para proporcionar o ressurgimento ainda mais significativo da "terra natal"? 


\section{Estudo de caso: a região de Tohoku no} Japão

Pretende-se perceber esses mecanismos de relação nostálgica na reconstrução da área destruída em 2011 por um terremoto seguido de tsunami no Japão. Esse evento natural foi catastrófico, pois afetou milhares de pessoas. Considerado extremamente violento, esse terremoto atingiu a magnitude de 8,9 Mw (MMS Moment Magnitude Scale) para um limite teórico máximo de $9 \mathrm{Mw}$. O efeito do terremoto que teve seu epicentro a apenas
$130 \mathrm{~km}$ da costa da península de Oshika (Miyagi) estimulou ondas gigantes (tsunami), que atingiram até 40,5 metros de altura (em Miyako) e devastaram o litoral nordeste do Japão, principalmente a província de Fukushima, onde um reator nuclear foi danificado e, com o superaquecimento, houve vazamento considerável de energia radioativa. ${ }^{1}$

1 Para maiores informações sobre esse desastre nuclear, ver: <http://en.rian.ru/infographics/ 20110315/163013616.html>. Acesso em: 10 abri. 2012.

Figura 1 - Epicentro do terremoto de Tohoku - 2011

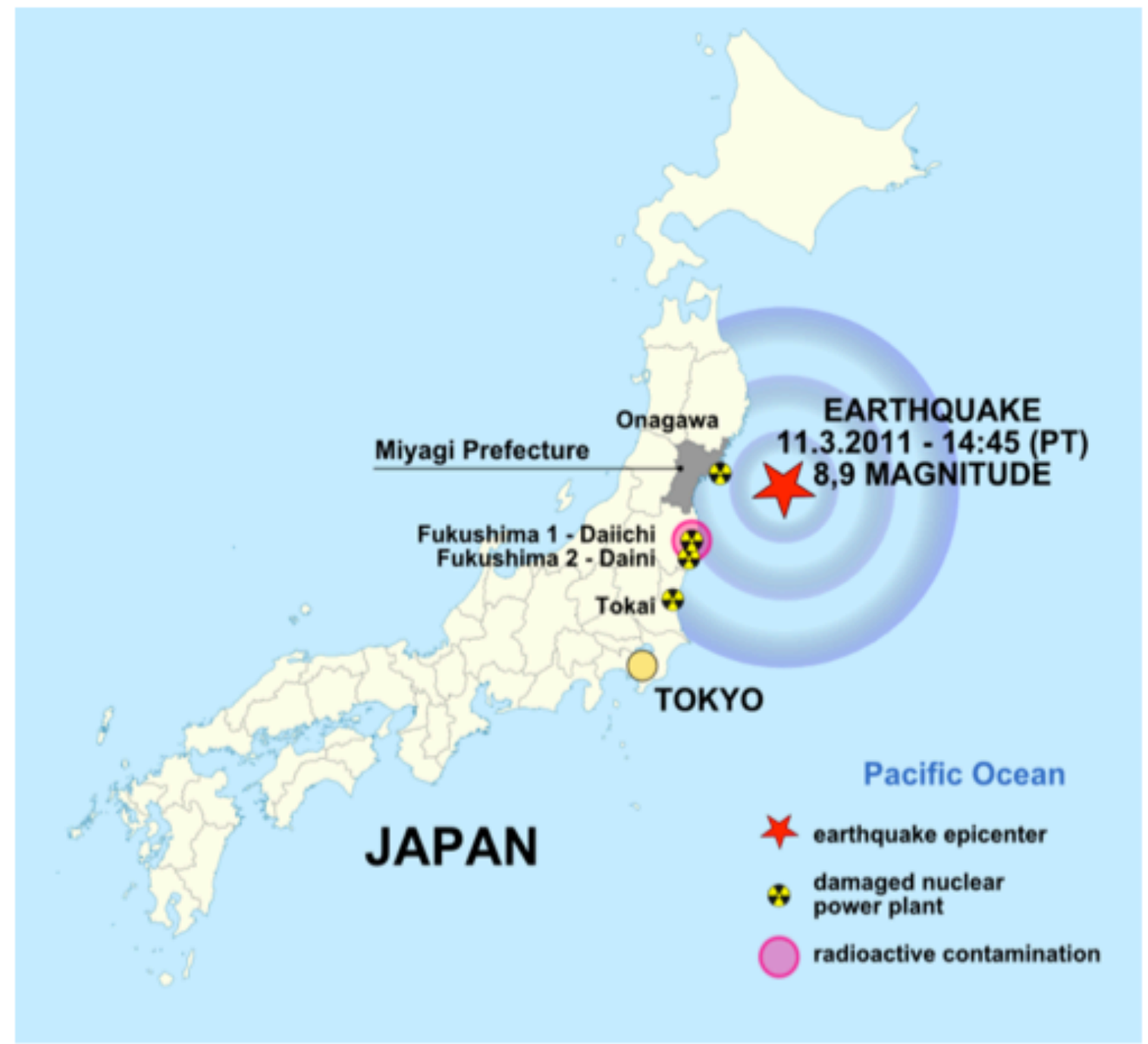

Fonte: Freehandyman (2011). 
A região de Tohoku (nordeste) do Japão é extremamente montanhosa e fria quase o ano todo. A divisão administrativa é realizada em seis províncias: Akita, Aomori, Iwate, Miyagi, Yamagata e Fukushima. A região apresenta muitas atrações históricas e naturais que promovem um forte comércio turístico para suas cidades. Assim como uma distinção cultural milenar, que é caracterizada, por exemplo, pelo kokeshi bonecos de madeira artesanais oriundos da região nordeste do Japão, que em si apresentam traços simbólicos que o definem de qual região ele foi feito, evidenciando assim o sentimento de furusato e nostalgia enquanto objeto de recordação ou lembrança regional (McDOWELL, 2011).

\section{O Japão já sofreu um desastre similar} em sua história contemporânea, foi o terremoto de Kobe, que atingiu 7.2 graus na escala Richter em 17 de janeiro de 1995. Mais de 6.000 pessoas perderam a vida e a destruição urbana foi extremamente significativa, o que não ocorria desde 1945 na Segunda Guerra Mundial. A Reconstrução de Kobe foi um exemplo de fidelidade com os traços originais do sentimento de "terra natal" entre os afetados, no entanto o terremoto não desconfigura o espaço por completo como fez o tsunami em Tohoku. O terremoto destrói e derruba edificações, no entanto o tsunami derruba e mistura tudo, desconfigurando por completo a paisagem local. Por isso são dois processos de reconstrução um tanto quanto distintos, pois muita coisa agora só existe na memória e não são passíveis de reconstrução fidedigna, como ocorreu em Kobe.

Figura 2 - As cidades mais afetadas pelo tsunami no Japão em 2011

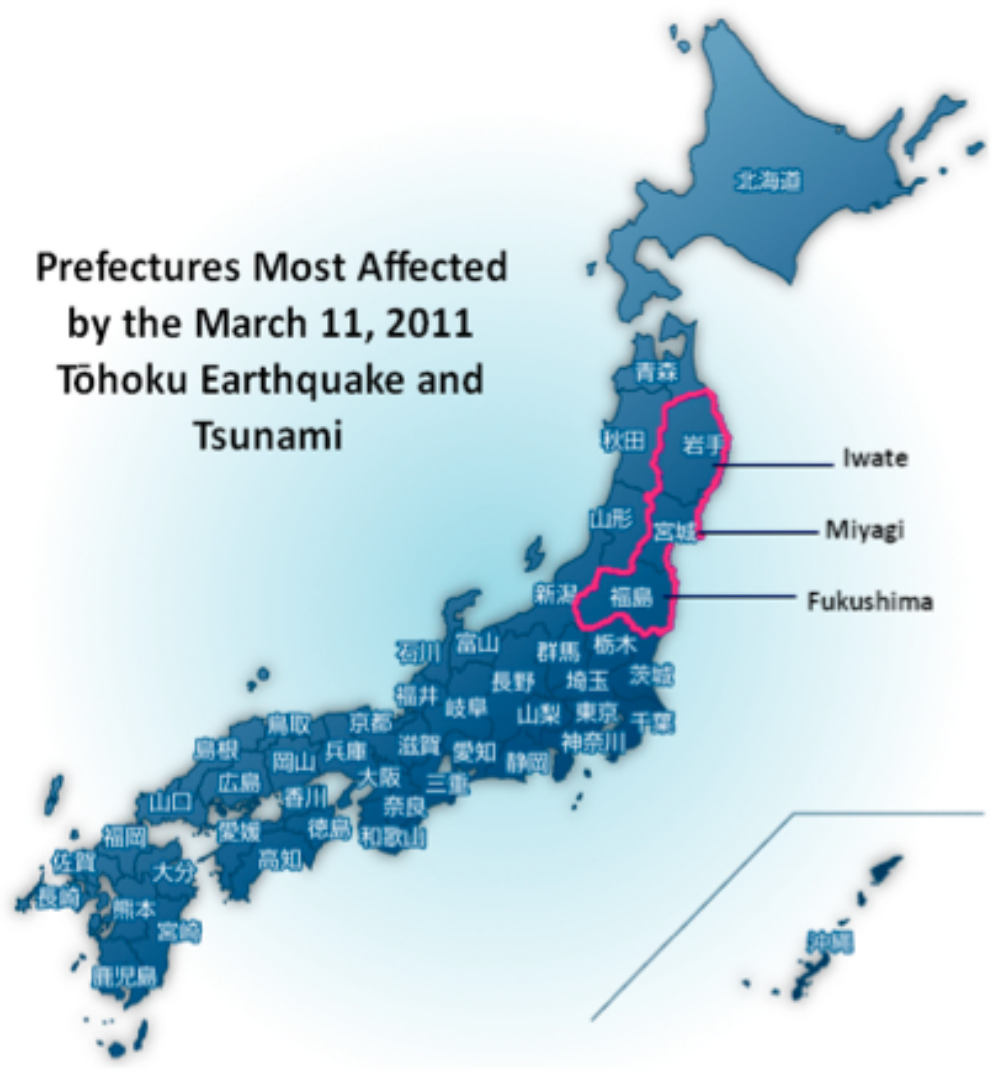

Fonte: Ruch e Siirilia (2011). 
Pode-se perceber na Figura 2 que as três províncias mais afetadas pelo terremoto/tsunami de 2011 foram Fukushima, Miyagi e Iwate, pois as ondas atingiram seu litoral. É nelas que faremos nosso recorte espacial para o estudo de caso.

\section{Etapas de reconstrução da área afetada de Tohoku}

Para o estudo desse caso em Tohoku mediado pelo senso paisagístico da "terra natal" pretendem-se dividir aqui em duas partes específicas: a primeira é sobre o processo de abrigo emergencial aos desabrigados do desastre de 2011, evidenciando quais seriam os mecanismos sensoriais traumáticos da perda total da "terra natal" incluindo a falta de privacidade e as construções leves de tentativas de personalizações do espaço, passando para estruturas intermediárias como casas escalonadas definitivas e/ou provisórias levando em consideração os fatores da reconstrução da paisagem interna familiar e de grupo. A segunda parte é sobre a paisagem desoladora, ou seja, o conceito aqui adotado de "paisagem zero", onde nada mais existe, no entanto é o ponto de partida para a "reconstrução da paisagem" que gera novos símbolos e fortalece o sentimento de furusato sustentado pela nostalgia emergente no pós-catástrofe.

Abrigos emergenciais e reconstrução primária do espaço pessoal

Para compreender como seria a constituição dos abrigos emergenciais e da reconstrução primária do espaço pessoal em Tohoku pode-se entender aqui através de uma tópica de análise, que se organiza em pontos baseados em estudos introdutórios de Psicologia Ambiental:

- percepção e cognição da paisagem: nesse ponto, pode-se analisar a vida socioespacial das pessoas afetadas e associar os problemas com a integridade simbólica da localidade aos resultados dessas alterações perceptivas e, portanto, cognitivas (GIFFORD, 1997, p. 16-45);

- o espaço e as pessoas: aqui, se pode pensar o espaço como o conceito de "lugar" na Geografia, ou seja, partindo de um fenômeno para o espaço (subjetivo) e, em contraponto, pensa-se o conceito de "paisagem" na Geografia como o espaço total que influência o fenômeno (atribuição objetiva). A psicologia nos ajuda com a pesquisa sobre as atitudes e personalizações no espaço (GIFFORD, 1997, p. 46117).

- organização do espaço pelos grupos: quanto mais organizado se mostra o espaço, mais coesa é a organização das pessoas em busca da formação e utilização de vias de "fluxo" e reconstrução dos "fixos" (lugares) através do símbolo, por exemplo: um pinheiro único (Ippon Matsu), que foi o único entre $70 \mathrm{mil}$ que resyou em pé na praia. $E$, sendo algo maiores que a soma dos fatores pessoais, os fatores sociais desencadeiam uma sensação de pertencimento a algo maior e mais duradouro, que agrega outras gerações (GIFFORD, 1997, p. 139170). 


\section{- reconstrução da identidade local:} nesse ponto, faz-se uma análise de como as pessoas se organizarão para fazer novamente o espaço coletivo da cidade, se as praças seriam as mesmas, no mesmo local, ou se existiriam outras ruas, com outros nomes, onde seria a prefeitura etc. e como ficaria a questão dos que não tiveram acesso as suas propriedades devido a radiação. Aqui também se pensa sobre a reconstrução considerando as paisagens e suas características onde a tipologia da paisagem seria como unidades padrões adequadas aos novos agenciamentos para a reconstrução da paisagem da terra natal (GIFFORD, 1997, p. 207-343).
Seguindo a lógica desses pontos iniciais de análise, notam-se a princípio a saúde das pessoas e os problemas com sua integridade biológica. Assim, se forneceram em união os mantimentos básicos para a sobrevivência, nas unidades emergenciais iniciais e nas propostas e experimentos pós-catástrofe. Os desabrigados foram destinadas a conviver em ginásios de esportes e barracões. Com o tempo, viram-se os efeitos da "privacidade zero" e a necessidade de certa constituição e respeito pelo espaço pessoal, que é comum a todos os seres humanos. Pensando nisso, se construíram divisórias baseadas em projetos do arquiteto Shigeru Ban. Feitas de materiais leves como plástico e papel, essas divisórias permitiram uma fácil mobilidade e, se preciso, uma rápida evacuação de emergência.

Figura 3 - Divisórias leves de emergência (Paper Partition System) oferecem privacidade visual

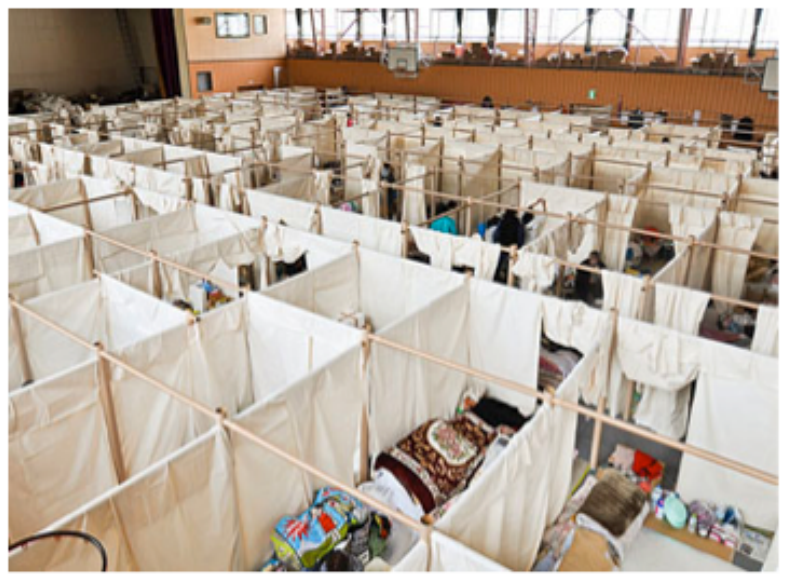

Fonte: Ban (2011).

O uso de tubos de papel para a construção de instalações e edificações é uma proposta que vem sendo desenvolvida pelo arquiteto Shigueru Ban (Figura 3). As divisórias modulares de tubos de papel mostraram-se úteis pela rapidez de montagem e rigidez estrutural. Garantem uma privacidade visual, mínima, para os abrigados em alojamentos. A falta de privacidade era motivo de stress e uma das principais reclamações dos desabrigados.

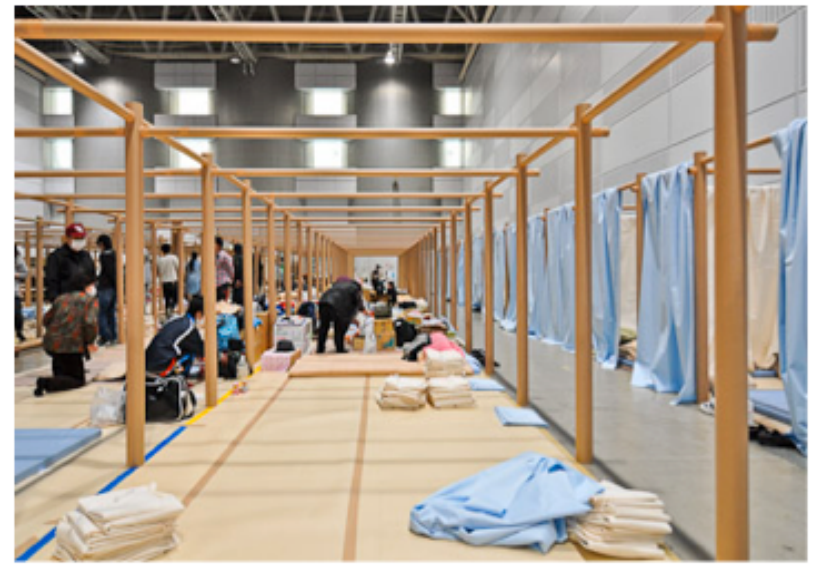

Logo em seguida, um grupo liderado pelo próprio arquiteto Ban propõe a construção de alojamentos familiares com containers, normalmente utilizados para transporte marítimo de carga. Os containers dão mais conforto térmico e condições de reconstrução da vida em família, ainda que sejam nulos como referencial de paisagem cultural. A Figura 4 mostra os detalhes da montagem de um dos conjuntos habitacionais construídos com essa tecnologia. 
Figura 4 - Habitações temporárias (Container Temporary Housing) que oferecem privacidade familiar, mas sem os referenciais imagéticos de terra natal
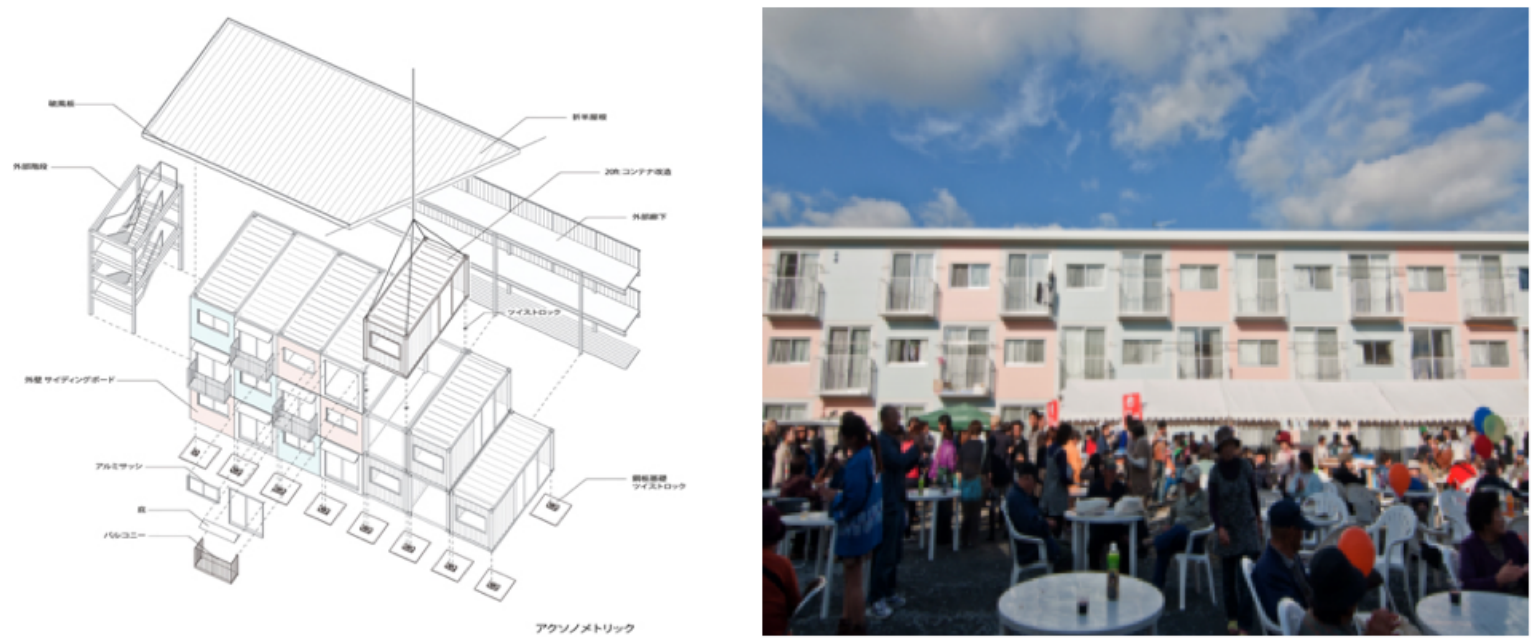

Fonte: Ban (2011).

O governo tem aplicado um grande esforço para tentar criar um senso de comunidade e resgatar o cotidiano. A organização de eventos e o resgate de festividades tradicionais fazem parte do processo de repensar o pertencimento.

Figura 5 - Escola, posto de saúde e templo construídos com tubos de papelão, segundo o projeto de Shigeru Ban
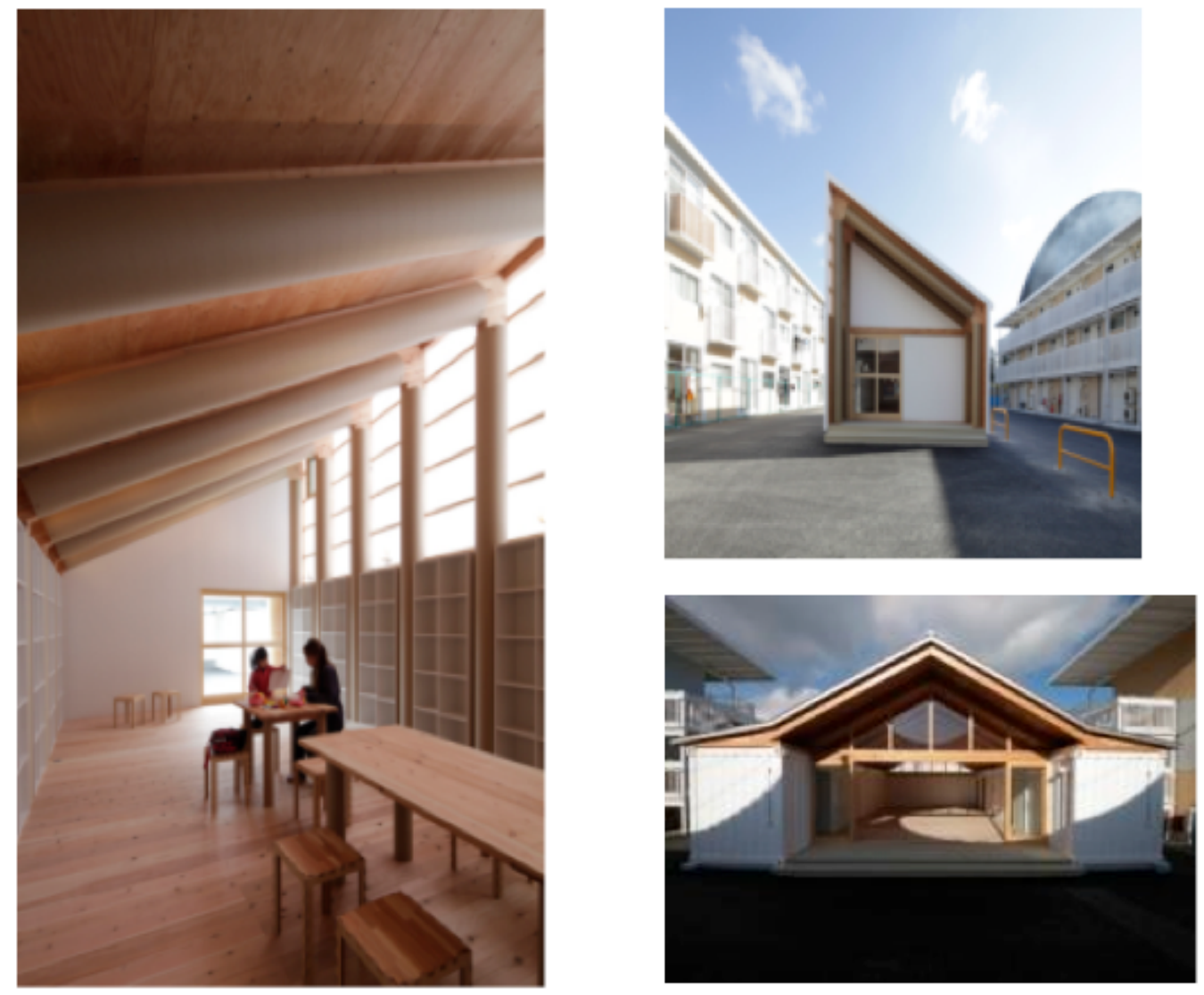

Fonte: Ban (2011). 
Solução possível integrada à paisagem

Apesar da rapidez de construção e do melhor controle térmico e acústico, as casas-containers são muito diferentes das tradicionais moradias de madeira com implantação dispersa encontradas no Japão.

Uma proposta de construção de abrigos resistentes a terremotos e seguindo uma implantação tradicional em regiões de escarpa foi proposta pelo Escritório de Arquitetura Alsed em 2004, na província de Niigata no Japão (Fig. 6 )

Segundo o memorial de projeto, a moradia segue 0 estilo arquitetônico tradicional de casas de madeira em Nagaoka, que são adaptadas à neve, que chega a se acumular cerca de três metros, nas áreas montanhosas, prevê o uso de recursos locais como fornecedores de material e construtores, têm um custo baixo e são duráveis - podem ser habitadas durante muito tempo.

Um outro tipo de solução

Além das casas temporárias em containers, há também as de madeira, com que se projetam vilas em sítios altos $\mathrm{e}$ adequados contra os perigos das forças naturais. Uma proposta são as casas típicas de madeira de dois andares com garagem na parte inferior.

Essas casas foram projetadas para áreas montanhosas e são resistentes a terremotos e adequadas para até três metros de neve. O projeto inicial tinha um custo baixo por ter sido comprado em grande escala para os desabrigados do terremoto de outubro de 2004 em Nagaoka e Yamakoshi, na província de Niigata. As vítimas retornaram às montanhas e, com isso, esse tipo de habitação tornou-se uma ótima opção, pois, além de economia e segurança, é confortável e preserva as características arquitetônicas tradicionais da região.

Essa preservação ou reconstrução da paisagem promovida por casas típicas e tradicionais da região promovem um forte sustento psicológico para o sentimento de pertencimento do "furusato", pois agrega uma tipologia regional que caracteriza determinada repartição espacial perante outros grupos similares e o faz cristalizar e estampar a simbologia desse local. Talvez seu efeito seja similar ao dos já mencionados kokeshi.

A vida das pessoas envolvidas em uma catástrofe como o terremoto de Tohoku de 2011 tende a despertar o modo como perceber a importância para se manter a ordem e a segurança da vida cotidiana citadina. Todas as gerações dos envolvidos e motivados pela causa direcionam os seus esforços voltados à reconstrução visando à conservação das tradições e o melhoramento dos mecanismos de defesa dessa localidade, assim como uma reconstrução potencializada pelo sentimento de furusato. A perda cultural foi grande nessa tragédia, somando o total de 754 lugares destruídos que eram destinados para a conservação da identidade local e formadores da paisagem da terra natal (furusato). Entre esses lugares 160 são casas e construções de memória histórica e 90 sítios históricos e arqueológicos, assim como teatros, lugares com monumentos e patrimônios naturais (BUNKA OHO, 2012). Com relação aos danos em patrimônios naturais e/ou culturais Matsushima merece 
uma atenção especial. Considerada uma das três maiores belezas naturais do Japão sofreu grandes danos após a passagem do tsunami. Além de milhares de jardins japoneses, que são espaços peculiares e carregados de sentido e significados (YOSHIKAWA, 1989). Como se reconstruirá essa paisagem?

Figura 6 - Moradias resistentes a terremotos integradas à paisagem

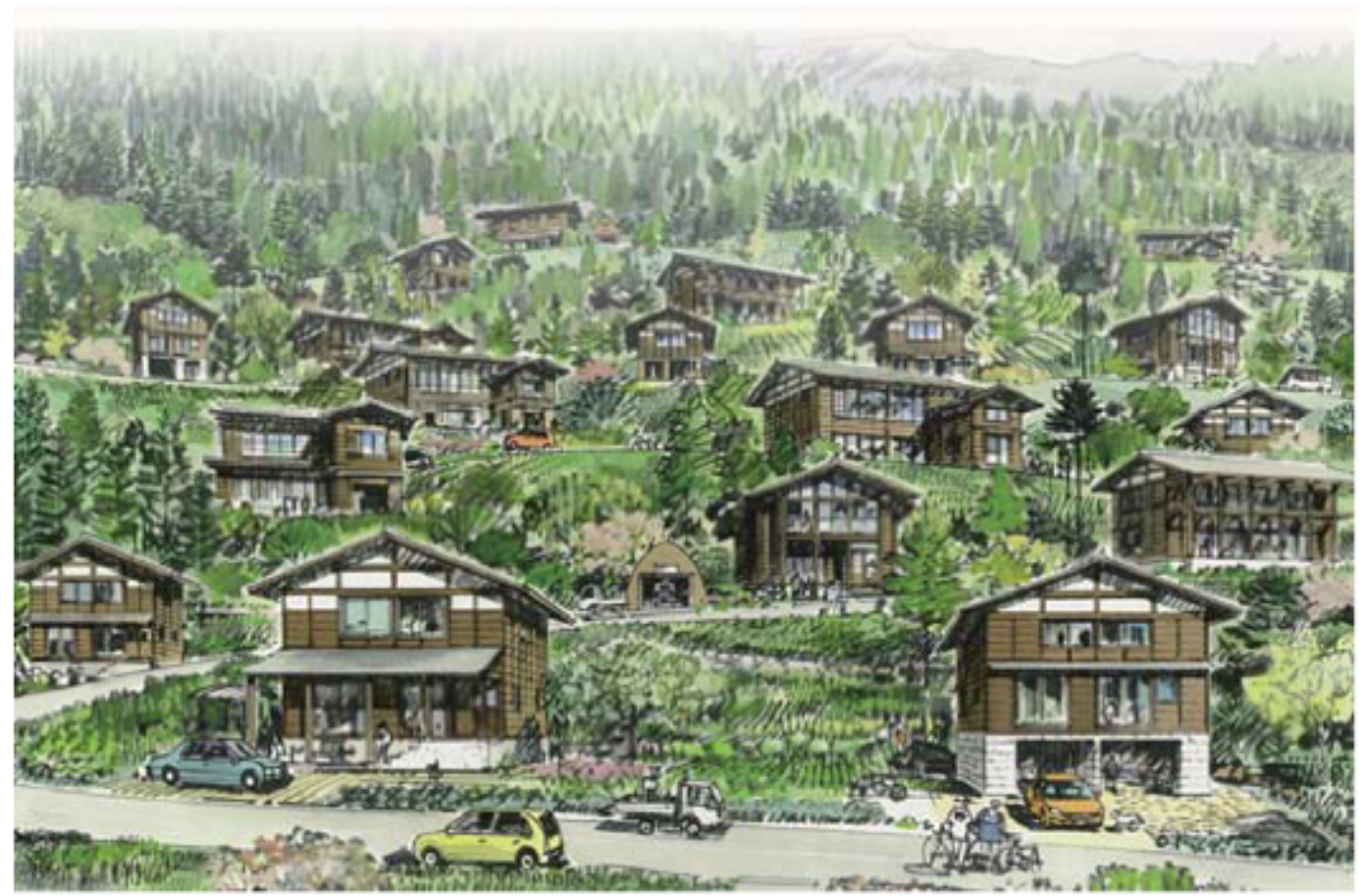

Fonte: Kouji et al. (2008).

A paisagem zero e a reconstrução da paisagem da terra natal

A reconstrução da paisagem da terra natal engloba mais do que o estudo sobre a reconstrução física da cidade destruída. Trata-se também sobre o modo como as pessoas sentem esse espaço em conformidade com uma espécie de necessidade interna topofílica. A realidade que envolve o grupo desperta uma melhora na conformidade com a vida se for ela de origem comum (terra natal). A ausência de "chão" cria um vazio muitas vezes preenchido com o suicídio ou alcoolismo, o que foi constatado entre alguns dos afetados e sobreviventes no terremoto de Tohoku de 2011. Essa ausência de chão seria um não se reconhecer no local:
Um dos lugares mais belos do mundo não pode dizer nada isolado, porque não se reconhece. Isto requer o diálogo entre o homem e o lugar que, mesmo que seja agradável, pode falhar em sua expressão, porque ninguém sabe nada a seu respeito, não representa nada, não nos reconhecemos nele (ANDREOTTI, 2010, p. 267).

A interdependência do lugar significativo e o homem é de suma importância para uma análise da reconstrução da paisagem da terra natal em termos arquitetônicos (ANDREOTTI, 2008, passim). $\mathrm{O}$ homem recria ambientes artificiais ou naturais como riachos e cachoeiras, para conseguir se "reconhecer" naquele local. Isso ocorre seja em imigrantes que levam consigo uma espacialidade matriz de sua terra natal e reproduzem aspectos 
similares no local a ser colonizado. Ou também se pode perceber essa lógica em locais que foram destruídos e precisam ser reconstruídos para o conforto identitário da cognição de seus habitantes.

Os modelos que melhor explicam a dinâmica entre a realidade compartilhada e a representação internalizada da paisagem são - que se pode chamar de modelos de associação intersubjetivo, que se concebem após uma retomada comparativa geral e coletiva dos mapas mentais da localidade vivida, desdobrando assim uma paisagem cotidiana da vizinhança.

Numa pesquisa realizada entre os moradores depois do terremoto de Kobe, foi constatado que os elementos perdidos e que eram considerados significativos eram de dois tipos: monumentos e edificações símbolos da cidade e a paisagem do cotidiano da vizinhança. Mostra a importância da paisagem do cotidiano na vida da comunidade em eventos catastróficos. Esse modelo de associação intersubjetivo da paisagem cotidiana pode capturar milhares de pontos particulares da cidade não representados em mapas ou fotos aéreas, no entanto nada pode substituir o verdadeiro sentimento da terra natal, a reconstrução arquitetonicamente nunca será exatamente a mesma, no entanto o sentimento de pertencimento da "terra natal" é reforçado, desse modo a reconstrução do ambiente destruído passa a ser um exercício laborioso da memória e da projeção do sentimento de nostalgia. A reconstrução é uma possibilidade de renovação. Os aspectos espaciais que não agradavam podem ser alterados. A vida recomeça através de uma análise interna, uma reflexão psicológica a priori de uma realidade mnemônica e futurista. O processo de limpeza dos escombros e entulhos (restos da materialidade original) ganha um significado modelador para essa psicologia do projeto futuro, pois desperta a memória e a nostalgia. Materiais recentes são misturados com objetos centenários em aglomerados de entulhos formando uma "paisagem desolada", e a história daquele local transforma-se em uma massa temporal homogênea sem distinção clara de ordem cronológica. O mundo-mente daqueles desabrigados passa a ser uma alegoria criativa, capaz de despertar uma nova possibilidade de vida, alimentada pela esperança de uma vida melhor e mediada pelos tristes escombros do passado destruído.

$\mathrm{Na}$ análise dessa "paisagem zero" capturável pelos sentidos ("seis"), pode-se pensar em mapas etários das construções. No entanto, isso não seria intimamente convivido no caso amplo das cidades afetadas de Tohoku, por exemplo, pois quase nada ficou em pé das construções. O velho e o novo se misturaram na "massa temporal homogênea" de entulhos $e$, dessa maneira, como pode-se pensar em faixas etárias do espaço urbano nesse caso de reconstrução? A resposta seria óbvia se o termo fosse "restauração", no entanto como não há esse ponto de partida danificado, e sim nada há exceto a memória interna subjetiva e alguns registros esporádicos; não é possível uma formalização etária do espaço. "A história nos leva a imaginar alguma coisa, mas a paisagem nunca é totalmente clara. Somos nós mesmos a paisagem" (ANDREOTTI, 2010, p. 267).

Os efeitos de teorias sobre esse mecanismo de ligação simbólica do homem com a terra nas discussões da Geografia não 
são novos, por exemplo, a obra L'homme et la terre, de Eric Dardel, de 1952. No entanto, outras obras do campo da fenomenologia são mais importantes e completas no tocante ao conceito de espaço e subjetividade. Ex abrupto, podem-se apresentar Henri Bergson, com a obra Ensaio sobre os dados imediatos da consciência, de 1886, Edmund Husserl, com Investigações lógicas, de 1901, e também, de modo mais cotidiano, Martin Heidegger, com O ser e o tempo, de 1927, e Jean-Paul Sartre, com o livro $O$ ser e o nada, de 1943. Além da filosofia contemporânea, encontra-se na Antropologia estrutural, de Claude Lévi-Strauss, de 1958, um bom apoio teórico sobre a questão de comportamento estruturado e universal, no entanto, antes desse, na área de psicologia, encontramos os Arquétipos e o inconsciente coletivo, de Carl Gustav Jung.

Baseados nesses autores e em reflexões próprias, pode-se perceber que os mecanismos que norteiam a "reconstrução" são antes de tudo psicológicos mnemônicos com atribuição de subjetividade coletiva (intersubjetivação). As simbologias (configurações coletivas) que envolvem cada integrante daquele processo de reconstrução carregam em si traços fortes de energia subjetiva, que não se revela aos olhos dos expectadores. São emoções vivenciadas e que não podem ser analisadas fora da pragmática vivência de tais fatos. Como por exemplo, o slogan adotado e espalhado por todos os lugares do nordeste do Japão: "Gambarou Tohoku" (Força, lute, Nordeste) desperta o sentimento dos que pertencem a esse local, um sentimento mais ligado ao ato de reconstruir com sangue do que ao descanso-destruído [sic] com lágrimas.
A maneira de se construir símbolos da reconstrução, como o "ippon matsu" (pinheiro único) que sobreviveu em pé dentre os 70.000 destruídos pelo tsunami faz um marco simbólico da reconstrução e resistência de Tohoku. Há também discussões sobre preservar símbolos memoriais do desastre, como deixar um navio no local onde foi parar após ser arrastado pelas ondas gigantes. Alguns alegam ser uma imagem negativa para 0 espírito da paisagem e gostariam que fossem removidos tudo que pudesse lembrar a tragédia.

Toda espacialização requer uma espécie de lógica de movimentos, que permita uma agilidade no deslocamento. Para tanto as ruas e vias são espaços fundamentais para esse feito. Como artérias e veias elas nutrem o organismo vivo da cidade passando assim a uma maneira não simplesmente e unicamente mecânica de fluxo vivo, mas sim uma paisagem, ou como Paulo Leminski chamaria "uma pele" da cidade, onde a estética expressa o sentimento interno, seja ele vazio e inconsciente de valor, ou rico e cheio de consciência e pertencimento.

Duas palavras de origem grega podem trabalhar em consonância e dualidade dentro do conceito japonês de furusato no processo de Reconstrução da Terra Natal, a primeira é a toponímia (o nome do lugar) que está muito ligada aos aspectos simbólicos que o "nome" recebe por suas fontes originárias: sejam elas de cunho etimológico fortemente influenciado por um idioma de origem mediada por fatos históricos, sejam pela formação estrutural (aspectos geológico-paisagísticos), ou por determinação de batismo oficializado (geralmente empregado 
em lugares planejados). A toponímia é um estandarte coletivo e que baliza as relações entre as localidades. A outra palavra grega é a topofília (lugar vivido), que na verdade é um neologismo famoso empregado pelo geógrafo Yi-Fu Tuan em 1974. A topofília é um sentimento afetivo positivo relacionado a um lugar, que quando afastado promove a nostalgia. Esse sentimento é subjetivo e não delimita recortes espaciais oficializados como é o caso da "toponímia". Uma espacialização de determinada pessoa ou grupo familiar analisada via topofília pode não ter uma relação espacial coerente com a toponímia do local. Por essa razão é importante levar em consideração no processo essas duas palavras e seus conceitos geográficos.

A "Terra Natal" demonstra ter forte pregnância e carregada de sentimento vivencial, uma verdadeira construtora de maquetes mentais, que precisa apenas de um incentivo para se projetar aos sentidos do sujeito. A Antropologia Estrutural revela padrões universais de artes humanas que são similares, porém não tem correspondência externa de ligação ou influência cultural entre os povos que a fizeram. A necessidade de habitação é um modelo arquétipo universal, no entanto o modo como cada povo constitui a paisagem dos locais habitados, ou seja, o modelo arquitetônico de cada habitação é muito peculiar. Em muitos casos há similaridades, tais como as pirâmides maias e as egípcias, ou os castelos europeus com os orientais (LÉVI-STRAUSS, 1985).

As estruturas naturais humanas para a arquitetura do espaço construído seguem uma tendência interior (subjetiva) padrão. No entanto o modo como é expresso essas manifestações espaciais variam entre os povos, muitas vezes influenciados pelos tipos de relações com o meio no qual pertencem, sendo, portanto parcialmente determinados pelo clima, tipo de madeira, relevo, hidrografia etc. No entanto, nem sempre as melhores maneiras de se pensar a reconstrução devem ser levadas como uma certeza de reprodução daquilo que interiormente se carrega, é preciso saber que a tendência humana universal pode se manifestar de modo alterado.

Precisa-se uma compreensão clara dessa ruptura lógica para se trabalhar com a "reconstrução da paisagem da Terra Natal", pois nem sempre será de modo idêntico como era, podendo sofrer alterações derivadas do senso de prevenção e defesa contra novos mecanismos destrutivos. $\mathrm{Na}$ verdade não se pode analisar a fidelidade dessa reconstrução, nem era o objetivo aqui, pois há uma potencialização do sentimento de furusato que não remete a uma paisagem idealizada mnemônica unicamente, mas sim a uma espécie de ligação essencial.

A coletividade trabalha em uma esfera temporal mais lenta e por essa razão suas mudanças são cotidianamente inconscientes. Não há uma real demonstração de agilidade de reconstrução quando se pensa no todo, tudo é uma questão de tempo, e ultrapassa gerações. Por essa razão a pessoa não é foco principal dessa análise, mesmo que apenas nela seja possível capturar esse "inconsciente coletivo", não é precisamente nela que podemos perceber, pois o tempo de alteração dessa consciência compartilhada em termos objetivos não traz significativa presença no indivíduo isolado, e sim na consonância entre o grupo que manifesta blocos de consciência dos antepassados e projetam esse corpo lógico aos descendentes. O "mundo-mente" é 
um artefato limitado para a compreensão do todo, porém não necessariamente por ser "menor" que o "inconsciente coletivo", mas sim por não termos a capacidade de extraí-lo para análise de uma única pessoa, mas sim de um todo amplo de grupal. Sem esquecer obviamente a máxima holística: "tudo tem tudo".

\section{Conclusão}

O estudo de reconstrução de Tohoku ainda está em fase inicial nesse projeto. No entanto, nossas primeiras impressões são as de que sustentamos nossa reflexão em uma ideia óbvia e simples que, entretanto, apenas pode ser confirmada como funcional e descritiva da realidade se for comprovada. E, a importância desse estudo se fundamente em confirmar a tese da "reconstrução da paisagem da Terra Natal" como um fortalecimento do sentimento de furusato. Da toponímia à topofília, com toda a carga simbólica coletiva. Algo que ultrapassa o senso de afetividade e seu recorte espacial subjetivo, pois o afeto afeta [sic] as estruturas subjetivas da pessoa, e mesmo que tudo tenha sido destruído e afetado, essas estruturas enraizadas ainda persistem e pode-se pensar que foram potencializadas, pois elas não estão na soma das partes e sim são o todo (gerações) não capturável da tradição que é a força motriz da reconstrução.

\section{Referências bibliográficas}

ANDREOTTI, G. Paisagens do espírito: a encenação da alma. Atêlie Geográfico, v. 4, n. 4, p. 264-280, dez. 2010.

\section{Per una architettura del} paesaggio. 2. ed. Trento: Valentina Trentini, 2008.

BAN, S. Disaster Relief Projects for Eatst Japan Earthquake and Tsunami, 2011a. Disponível em:

<http://www.shigerubanarchitects.co m/SBA_NEWS/SBA_news_5.htm > . Acesso em: 5 maio 2012.

. Container Temporary Housing, 2011b. Disponível em:

<http://www.shigerubanarchitects.co m/SBA_NEWS/SBA_van_p2.htm >. Acesso em: 6 maio 2012.

BERGSON, H. Ensaio sobre os dados imediatos da consciência. Lisboa: Edições 70, [1927?][1889].

BUNKA OHO. Agency for Cultural Affairs. Damages to Cultural Properties in the "the Great East Japan Earthquakes". Disponível em: <http://www.bunka.go.jp/english/ind ex.html>. Acesso em: 17 abr. 2012.
FREEHANDYMAN. Tohoku Earthquake Map, 2011. Disponível em: <http://freeandhandy.com/practicaltips-in-preparation-for-earthquakesand-other-natural-disasters/tohokuearthquake-map/>. Acesso em: 20 mar. 2012.

FUKUSHIMA PREFECTURE. Sights in Fukushima Japan: Tourism Information of Fukushima Prefecture, 2011. Disponível em: <http://fukutabi.jp/en/comments/2011/07/00083 5.html>. Acesso em: 8 maio 2012.

GIFFORD, R. (Org.). Environmental Psychology: Principles and Practice. 2nd ed. Boston: Allyn \& Bacon, 1997.

GUNN, A. M. Encyclopedia of Disasters: Environmental Catastrophes and Human Tragedies. V. 1. London: Greenwood Press, 2008.

HEIDEGGER, M. Ser y tiempo. Trad. Jorge Eduardo Riveira. Santiago: Arcis, s.d.[1927].

HUSSERL, E. The Shorter Logical Investigation. New York: Routledge, 2001. 
JONKMAN, S. N.; VRIJLING, J. K.; VROUWENVELDER, A. C. W. M. Methods for the Estimation of Loss of Life due to Floods: a literature review and a proposal for a new method. Nat Hazard, v. 46, p. 353-389, 2008.

JUNG, C. G. Os arquétipos e o inconsciente coletivo. Petrópolis: Vozes, 2000.

\section{KINDA, A. (Org.). A Landscape History of} Japan. Kyoto: Kyoto University Press, 2010.

KOUJI, T. et al. Reconstruction Housing Models for Earthquake Damaged Areas in Yamakoshi, 2008. Disponível em: <http://www.alsed.co.jp/2news/ mokuzo_kasetsu/yamakoshi_fukkojut aku.pdf $>$. Acesso em: 11 jun. 2012.

\section{LÉVI-STRAUSS, C. Antropologia estrutural.} 2. ed. Rio de Janeiro: Tempo Brasileiro, 1985.

McDOWELL, J. E. Kokeshi: continued and created traditions (motivations for a japanese flok art doll). Pittsburgh: University of Pittsburgh, 2011.

ROBERTSON, J. Hegemonic Nostalgia, Tourism, and Nation-Making in Japan. Senri Ethnological Studies, v. 38 , p. 89-103, 1995.
. Furusato Japan: The Culture and Politics Nostalgia. International Journal of Politics, Culture, and Society, v. 1, n. 4, p. 494-518, Summer 1988.

RUCH, G.; SIIRILA, A. Tohoku Region Matters for America, 2011. Disponível em: <http://www.japanmattersforamerica .org/2011/03/tohoku-region-mattersfor-america/>. Acesso em: 28 abr. 2012.

SARTRE, J.-P. O ser e o nada: ensaio de ontologia fenomenológica. 12. ed. Petrópolis: Vozes, 2003[1943].

TARANTINO, A. G. (Org.). Governance, Risk, and Compliance Handbook: Technology, Finance, Environmental and International Guidance and Best Practices. New Jersey: John Wiley \& Sons, Inc., 2008.

YOSHIKAWA, I. Stone Basins: the accents of Japanese Garden. Tokyo: Graphicsha Publising, 1989.

WETMORE, F.; JAMIESON, G. Flood Mitigation Planning: The CRS Approach. Natural Hazards Informer, n. 1, jul. 1999.

WRIGHT, J. K. Terrae incognitae: the place of imagination in Geography. Annals of the Association of American Geographers, v. 37 , n. 15, p. 1-15, 1947. 